\title{
NOTE ON THE QUALITY OF THE PAPER EMPLOYED BY THE DAILY PRESS.
}

By Alfred H. Allen, F.C.S.

Read before the Sooiety of Public Analysts, at Sheffeld, on 22nd August, 1879.

Some two years since I had occasion to inquire into the quality of the paper supplied to a well-known daily paper, and I then incidentally examined the paper employed for various prominent newspapers, with the aim of ascertaining whether the paper in question was better or worse than the generality.

The plan of inquiry adopted was a very simple one. A strip of paper one inch wide and twelve inches long was cut from the edge of the newspaper. It was then well dried in a water-oven, and its weight taken. This was calculated to the square foot of paper. The strip of paper was then burnt, and the ash weighed. This weight was calculated to a percentage of the weight of the original strip.

The following table shows the results yielded by the leading daily papers. The papers are arranged in the order of their quality, as measured by the weight of the paper less that of the ash. This plan gives an approximation to the amount of the fibre, but of course the results are nothing more than rough comparisons as the quality of the paper is liable to accidental variation from several causes.

- We are compelled to hold over this paper until our next number.-EDs. ANaLYsT. 


\begin{tabular}{|c|c|c|c|c|c|c|c|c|c|}
\hline \multirow[b]{2}{*}{1.} & \multicolumn{2}{|l|}{ Namo of Paper. } & \multicolumn{5}{|c|}{$\begin{array}{l}\text { Weight of Paper in grains per square foot. } \\
\text { Total Weight. Excluaive of Ash. }\end{array}$} & \multicolumn{2}{|c|}{ Percentage of Ash. } \\
\hline & Morning Post .. & .. & .. & $110 \cdot 4$ & .. & $104 \cdot 1$ & .. & .. & $5 \cdot 7$ \\
\hline 2. & Times & .. & .. & $90 \cdot 5$ & .. & $77 \cdot 7$ & .. & .. & $14 \cdot 1$ \\
\hline 3. & Pall Mall Grazette... & .. & .. & $94 \cdot 2$ & .. & $76 \cdot 8$ & .. & .. & $18 \cdot 4$ \\
\hline 4. & Birmingham Daily Post & .. & .. & $82 \cdot 2$ & .. & $75 \cdot 1$ & .. & .. & $8 \cdot 6$ \\
\hline 5. & Daily Telegraph .. & .. & .. & $71 \cdot 1$ & .. & $66 \cdot 5$ & .. & .. & 6.4 \\
\hline 6. & Plymouth Post & .. & .. & $68 \cdot 8$ & .. & $65 \cdot 2$ & .. & .. & $5 \cdot 4$ \\
\hline 7. & Sheffield Daily Telegraph & $2 .$. & $\because$ & $71 \cdot 3$ & .. & $63 \cdot 0$ & .. & .. & 11.5 \\
\hline 8. & Bristol Daily Post.. & .. & .. & $67 \cdot 7$ & .. & $62 \cdot 5$ & .. & .. & $7 \cdot 6$ \\
\hline 9. & Daily News.. & .. & .. & $67 \cdot 7$ & .. & $61 \cdot 0$ & .. & .. & $10 \cdot 0$ \\
\hline 10. & Western Morning News & .. & .. & $68 \cdot 7$ & .. & $61 \cdot 0$ & .. & .. & $11 \cdot 4$ \\
\hline 11. & Standard $\quad$.. $\quad$.. & .. & .. & $71 \cdot 1$ & .. & $60 \cdot 2$ & .. & .. & $15 \cdot 3$ \\
\hline 12. & Globe & .. & .. & $69 \cdot 8$ & .. & $59 \cdot 1$ & .. & .. & $14 \cdot 2$ \\
\hline 13. & York Herald & .. & .. & $65 \cdot 5$ & .. & $58 \cdot 5$ & .. & .. & $10 \cdot 8$ \\
\hline 14. & Manchester Guardian & .. & .. & $64 \cdot 1$ & .. & $58 \cdot 2$ & .. & .. & $9 \cdot 2$ \\
\hline 15. & Leeds Mercury & .. & .. & $63 \cdot 7$ & .. & $57 \cdot 3$ & .. & .. & $10 \cdot 1$ \\
\hline 16. & Manchester Examiner & .. & .. & $67 \cdot 7$ & .. & $56 \cdot 4$ & .. & .. & $12 \cdot 9$ \\
\hline 17. & Liverpool Daily Post & .. & .. & $59 \cdot 3$ & .. & $56 \cdot 2$ & .. & .. & $5 \cdot 1$ \\
\hline 18. & Echo... & .. & .. & $68 \cdot 7$ & .. & $56 \cdot 0$ & .. & .. & $18 \cdot 3$ \\
\hline 19. & Yorkshire Post & .. & .. & $64 \cdot 2$ & .. & $54 \cdot 4$ & .. & .. & $15 \cdot 4$ \\
\hline 20. & Liverpool Mercury.. & .. & .. & $60 \cdot 8$ & .. & $53 \cdot 3$ & .. & .. & $12 \cdot 3$ \\
\hline 21. & Sheffield Independent & .. & .. & $62 \cdot 5$ & .. & $51 \cdot 7$ & .. & .. & $17 \cdot 4$ \\
\hline 22. & Western Daily Press & .. & .. & $58 \cdot 3$ & .. & $50 \cdot 1$ & .. & .. & $14 \cdot 0$ \\
\hline
\end{tabular}

These results clearly show, as might have been expected, that the Morning Post and Times papers are heavier and stronger than those employed for the penny press. The difference between the ash of these two papers is, however, somewhat striking, and other curious points will occur to anyone inspecting the figures.

The weight and percentage of ash of paper furnish the usual commercial tests of quality, and although these factors are not the only ones which should be taken into account in forming an opinion, they are of considerable importance, and hence the figures recorded may be of service to chemists engaged on similar inquiries, as they show what newspaper should contain. Other things being equal, the paper will be better the greater its weight per square foot. The ash, of course, indicates so much mineral matter added to give weight, substance, and surface; and, as it does not add to the strength, it should be deducted before making a comparison of the quality.

The determinations recorded in the table were made in my laboratory by Mr. Charles Harrison.

I may add that the colouring matter which gives the Globe its roseate hue is aniline red. It may readily be dissolved out of the paper by alcohol. 